\title{
Circuit Design for QoS Routing Strategy Based on Target Searching Algorithm
}

\author{
Furong Tian \\ Tourism College, Kunming University, Kunming, 650214, China \\ furong_tian@yeah.net
}

Keywords: Risk measurement, Target perception, QoS routing, Price index, Distribution test, Search.

\begin{abstract}
In order to realize the hotel online booking price risk measure, this paper puts forward a strategy of multi-path QoS routing based on target perception, using the market risk value measures the hotel online reservation price risk. Through the wireless Mesh model, the establishment of hotel reservation price client network carries out empirical analysis on the five-star, four-star and Samsung hotel online reservation price index as the source of data and carries out the related distribution models to test the data, and then using the QoS risk target search calculates market risk value, which improve a reliable computer target search algorithm for the study of hotel online booking price.
\end{abstract}

\section{Introduction}

The hotel industry is a higher degree of marketization industry, the guest room price will change with the market factors fluctuate, and hotel room price fluctuations will make the hotel managers facing certain financial and management risks, thereby affecting the hotel's economic and consumer welfare [1-3]. Therefore, through the study and analysis of the hotel online reservation price, the use of certain methods grasps its fluctuation law, and the hotel carries out more effective management and control that have important practical significance [4,5]. This paper uses the QoS node searching path to optimize the design of the hotel risk measurement model, in which the overall frame is shown in Figure 1.

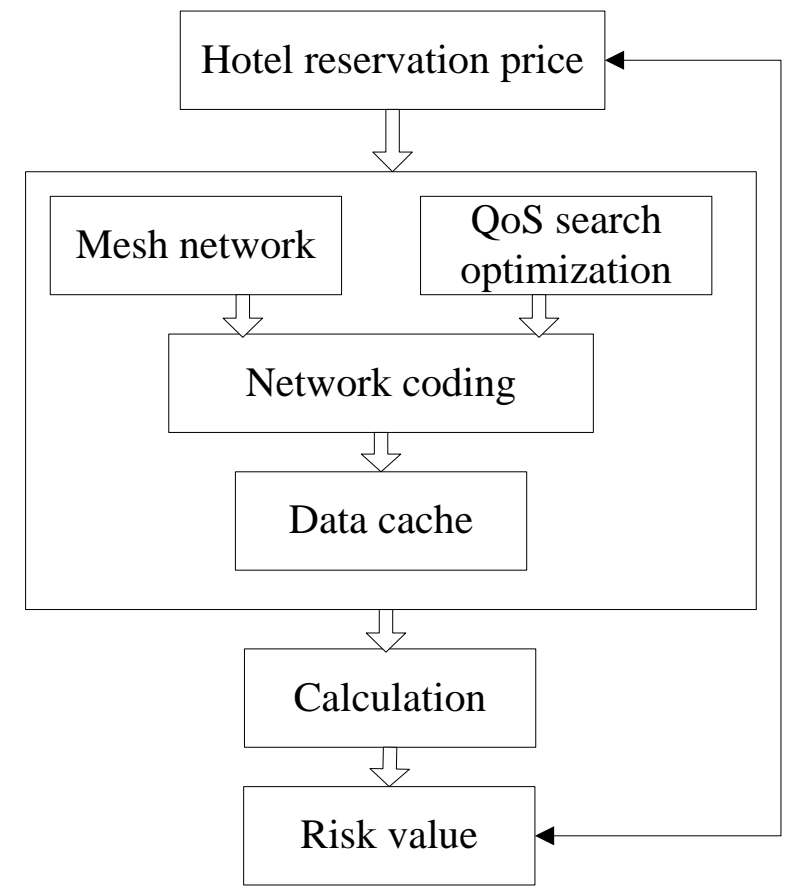

Fig.1: The framework of hotel risk measurement QoS optimization model

Figure 1 shows the basic framework of hotel risk measurement QoS optimization model, Mesh model is the formation of the client network of hotel network pricing to search the risk using QoS algorithm [6-8]. Through network coding, the pricing data are cached and calculated, we can get the 
risk value.

\section{Design of Mesh Network Object Detection Mathematical Model and Algorithm}

In order to search the hotel network reservation price risks, using the target detection method realizes the multi hotel mean risk measurement model, this paper uses QoS model to optimize the design of path search, in which the schematic is shown in Figure 2.

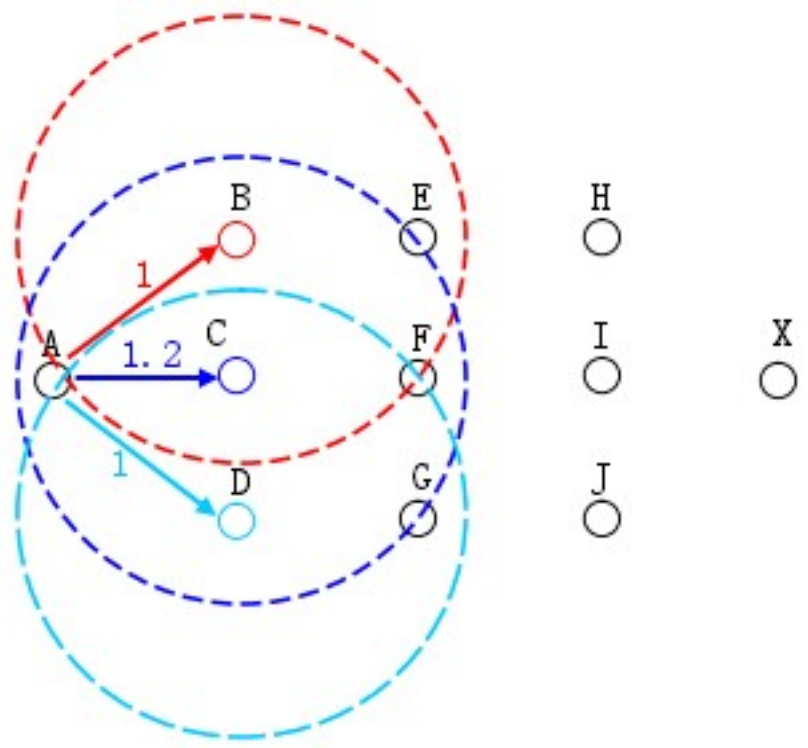

Fig.2: Schematic diagram of target search

As shown in Figure 2, $A$ shows the source node of target search, $B, C$ and $D$ are its neighbor nodes and are on the hop node, at the same time each node is infected with different colors, which represents the possible different paths [9-11]. Firstly, we need to calculate each path QoS performance function value, in which the formula is

$$
\frac{d y(x)}{d x}=g\left(x_{1}, x_{2}, \cdots, x_{n}\right)
$$

Among them, $x$ represents time, $g(x)$ represents target function. Assuming the higher order terms of Taylor expansion in formula (1) is $e\left(x_{1}, x_{2}, \cdots, x_{n}\right)$, so Taylor expansion can be written as

$$
\frac{d y(x)}{d x}=\sum_{j=1}^{n} e_{j} c_{j} \quad j=1,2, \cdots, n \text {. }
$$

Then, QoS target search algorithm model can be written as

$$
X=\frac{d g(x)}{d x}=\lambda 1 g(x)+\lambda 2 g(x), V_{x}=\frac{d y}{d x} .
$$

Among them, $V$ shows search speed, the value of $\lambda$ can use the following formula to calculate.

$$
\lambda=\arctan \left(\frac{\mathrm{V}_{\mathrm{x}}}{\mathrm{V}_{\mathrm{y}}}\right) \text {. }
$$

In order to achieve QoS target search algorithm to achieve optimal design of hotel risk measuring model, this paper uses the programming way to achieve target algorithm, in which the main algorithms are as follows [12,13]:

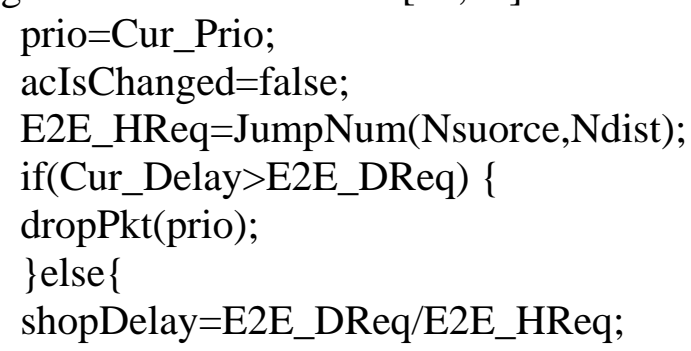




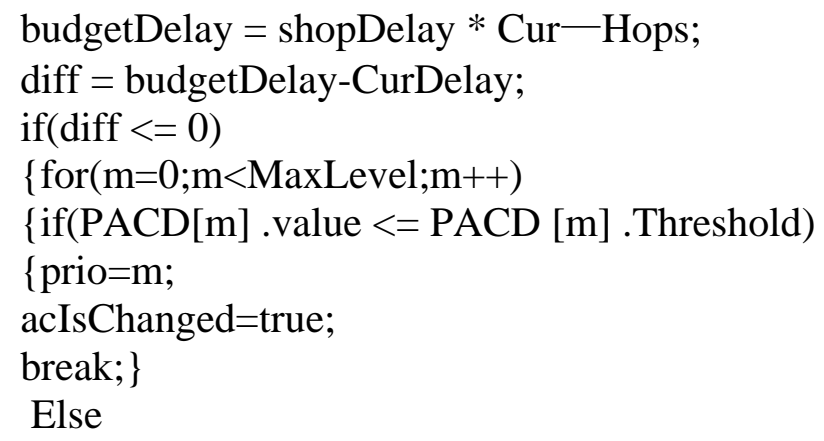

\section{The Calculation of the Hotel Online Pricing Target Detection Risk Measurement based on Mesh Network}

In order to verify the effectiveness and reliability of target detection mathematical model designed in second part, the 300 hotel network pricing client carry out network, this paper designs the wireless mesh network between hotel reservation price, and the use of QoS path carries out the changes of real-time monitoring hotel network pricing, in which the mesh path diagram is shown in Figure 3.

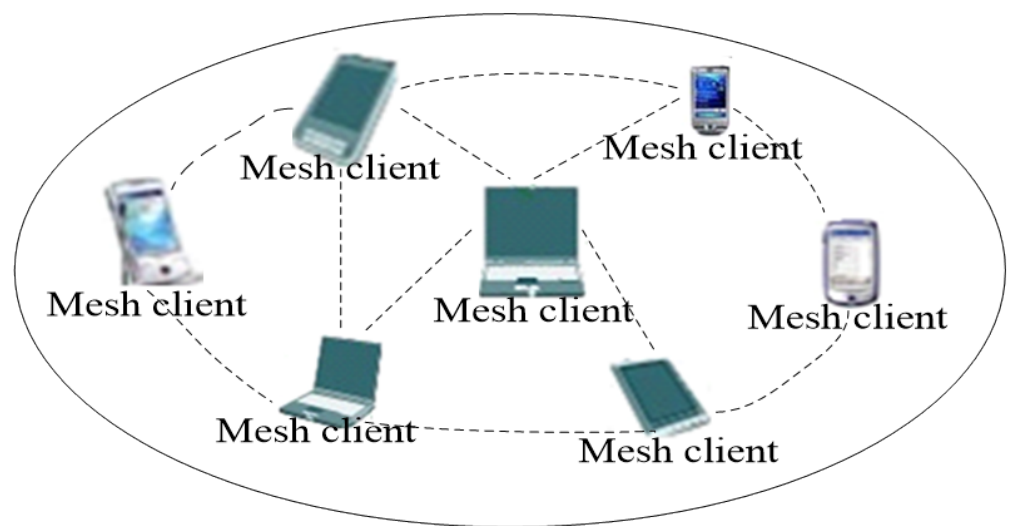

Fig.3: Schematic diagram of wireless mesh network

As shown in Figure 3, it indicates the client wireless Mesh network structure, the network uses wireless link between Mesh customers that is the formation of a small wireless multi hop network $[14,15]$. The hotel goes through the network to carry on direct communication, and farther distance can use the relay to realize the function of communication.

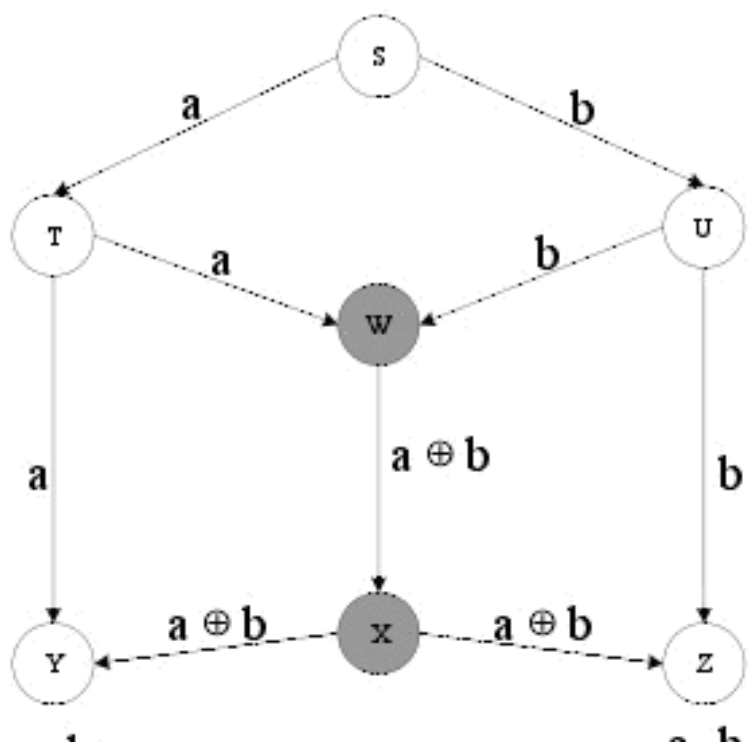

a b

Fig.4: Network coding method 
In order to realize the target search of QoS path, nodes use network coding method work [16]. As shown in Figure 4, the received risk data packet allows an encoding operation in network nodes; when we receive the data packet of higher risk index, it will be passed to the $Y$ and $Z$ by XOR operation.

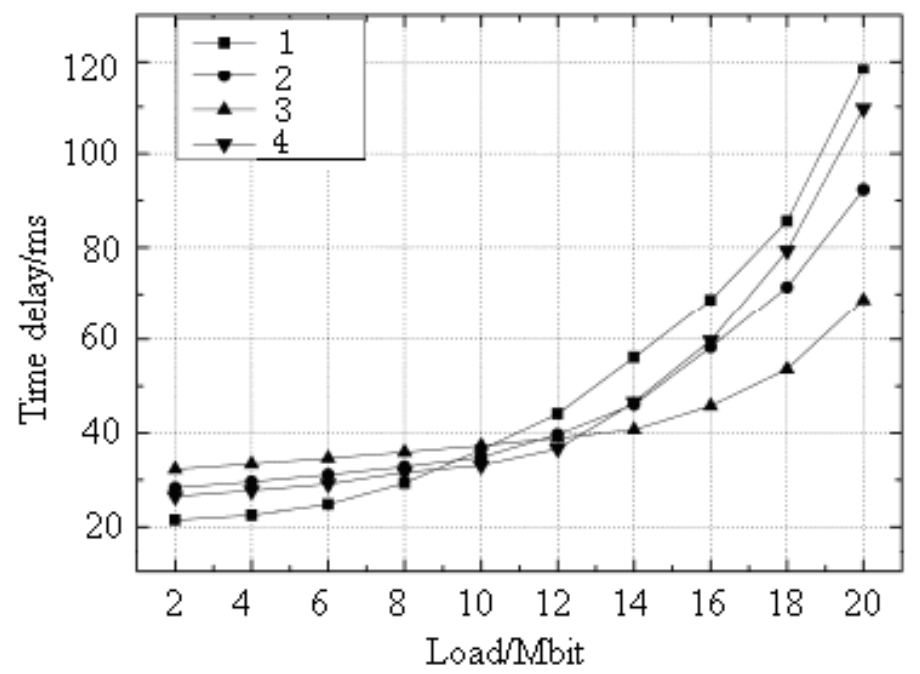

Fig.5: Delay characteristics curves under the different loads

Figure 5 shows the delay characteristic curve under the different loads. In order to increase the effectiveness and reliability of the test, this paper does four different tests for the same mesh network, the results can be seen that the delay of each test values are not more than $120 \mathrm{~ms}$, which is consistent with the need of calculation system.

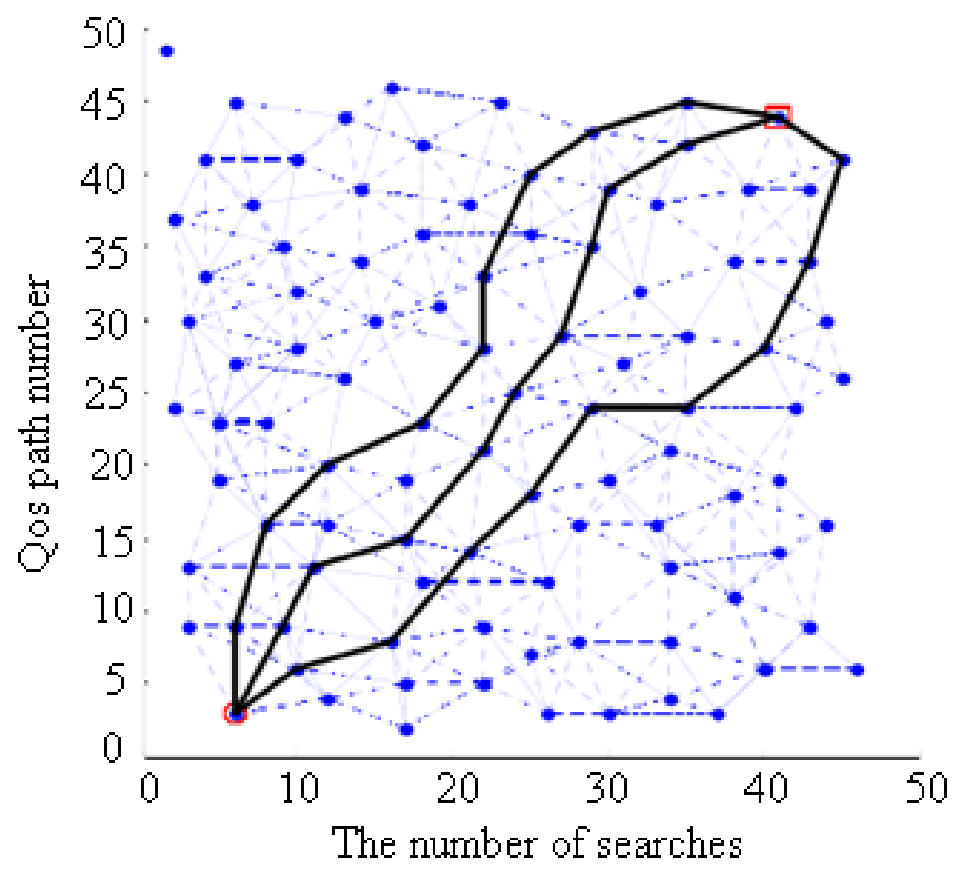

Fig.6: Hotel network pricing risk search process

Figure 6 shows the calculation process of hotel network pricing risk, the use of QoS target path detection principle and the QoS node path carry out risk assessment for each localized hotel price, and the source node search ultimately gets the target node [17]. Through calculation, the results are obtained as shown in Figure 7. 
Table 1: Online booking price risk assessment

\begin{tabular}{llll}
\hline Test items & Samsung & Four-star & Five-star \\
\hline Mean & 0.01625 & 0.00382 & 0.00985 \\
Skewness & 5.2326 & 0.4526 & 0.8796 \\
Kurtosis & 22.5212 & 10.2365 & 8.2569
\end{tabular}

In Table 1, it can be seen that the mean of each hotel market price RSV sequences are slightly greater than 0 , it shows that the stars hotel market prices are around its long-run trend fluctuated, and the market price is higher than the trend of the price. The hotel market risk can be large, and the random fluctuations of the market price are above $10 \%$ in the relative minimum values. So in the network pricing, we need to consider network market mechanism to avoid the pricing risk using the price equilibrium means, the hotel price coincides with the actual market prices.

\section{Summary}

(1) Based on the Mesh wireless network model, this paper proposes a new hotel online reservation price risk measurement model using QoS routing optimization strategy, and using programming way achieves the target algorithm to realize the optimization model of hotel reservation price risk search.

(2) By verifying hotel reservation price client network and extracting data, the data analysis results show that the hotel market risk can be large, the minimum values of the relative stochastic volatility market price are above $10 \%$, which provides a new computer method for the study of hotel network reservation price.

\section{References}

[1] R.L. Dai. Study of the property hotel investment risks based on game theory. Science technology progress and policy, 2010(19): 81-84.

[2] Y.X. Zhang, C.Y. Xu, J.H. Cheng. The price risk assessment of China petroleum enterprise transnational merger based on VaR method. Journal of management, 2010(3): 34-38.

[3] Q. Zhang, C. Wang, K. Wang. China livestock market price risk measurement and analysis. Economic issues, 2010(3): 78-81.

[4] Y.H. Lv, Y.Q. Xu. Discussion on hotel service product innovation risk early warning management system. Economic forum, 2012, 3(4): 56-59.

[5] J.H. Zhao. Construction and application of hotel financial risk early warning index system. Journal of Zhengzhou University of Light Industry, 2012, 4(1): 24-28.

[6] J.C. Zong, W. Huang, J. Ma. An Empirical Study on the price dispersion in the hotel online booking-- Beijing, Shanghai and Guangzhou as the cases. Nankai business review, 2012(1): 114-116.

[8] Z.J. Cao, S.P. Wang. Compared with Chinese and foreign tourism research content and the development of China tourism research trend based on Annals of Tourism Research and "Tourism Tribune" literature theory. Journal of Inner Mongolia Finance and Economics College, 2012, 3(30): 45-48.

[9] Y. Chen, B.J. Yang. Overview of The technology acceptance model theory development research. Science technology progress and policy, 2012, 3(4): 12-15.

[10] D.R. Lin, X.L. Guo. A review of tourism electronic commerce research. Journal travel, 2012, 3(5): 34-38.

[11] X.L. Wu, X.J. Zhou. Overview of tourism website research. Business culture, 2012 3(1): 34-37.

[12] L. Li, J. Wang. Analysis of China tourism electronic commerce consumer purchase decisionmaking behavior From the "onlooker" to "buyer". Journal of travel, 2012, 3(8): 78-80. 
[13] L.M. Yang, B.X. Lao. Impact of electronic commerce on the traditional tourism value chain. Chinese circulation economy, 2012, 3(8): 23-26.

[14] B. Geng. Influence of safety and commodity quality perceived risk on online shopping behavior. Science and technology information, 2013, 4(5): 45-48.

[15] J.W. Qiu. Analysis of tourist and its consumption behavior under the internet background. Industry technical and economic, 2013(4): 12-16.

[16] Y.P. Chang, D.H. Zhu. Research on the effects factors of online shopping intention based on consumer innovation perspective. Journal of management, 2012, 4(1): 91-95.

[17] Z.C. Song, G.M. Zhu. Study on the depth development of world cultural heritage tourism taking Qufu as the case. Journal of travel, 2012, 4(2): 45-48. 